\title{
A biophysical and economic model of agriculture and water in the Murray-Darling Basin, Australia
}

\author{
M. Ejaz Qureshi ${ }^{\mathrm{a}, \mathrm{e}, *}$, Stuart M. Whitten ${ }^{\mathrm{a}}$, Mohammed Mainuddin ${ }^{\mathrm{b}}$, Steve Marvanek ${ }^{\mathrm{c}}$, Amgad Elmahdi $^{\mathrm{d}}$ \\ ${ }^{a}$ CSIRO Ecosystem Sciences, Black Mountain, ACT 2601, Australia \\ ${ }^{\mathrm{b}}$ CSIRO Land and Water, Black Mountain, ACT, Australia \\ ${ }^{c}$ CSIRO Land and Water, Glen Osmond, SA, Australia \\ ${ }^{\mathrm{d}}$ Bureau of Meteorology, Melbourne, Vic, Australia \\ ${ }^{\mathrm{e}}$ Fenner School of Environment $\mathcal{E}$ Society, ANU, Australia
}

\section{A R T I C L E I N F O}

\section{Article history:}

Received 24 May 2012

Received in revised form

13 November 2012

Accepted 18 November 2012

Available online 25 December 2012

\section{Keywords:}

Economic models

Optimisation

PMP

Mathematical

Water policy

\section{Introduction}

The Murray-Darling Basin (MDB), which is the major irrigation area of Australia, has faced irrigation water overallocation compounded by reduced future rainfall due to climate change (CSIRO, 2008). According to the baseline assessment of water resources for the National Water Initiative, the total sustainable yield for the MDB was $14,533 \mathrm{GL}$ while the total entitlements in the MDB were 18,368 GL (NWC, 2007) suggesting about $25 \%$ overallocation. Future climate change is expected to reduce rainfall with consequent effects on surface water availability in the southern Murray-Darling Basin (SMDB). Projected future climate change impacts suggest a decreased and more variable future water supply for irrigation. A median scenario is expected to result in $10876 \mathrm{GL}$ water available for

\footnotetext{
* Corresponding author. CSIRO Ecosystem Sciences, Black Mountain, ACT 2601, Australia. Tel.: +6126246 4322 .

E-mail addresses: Ejaz.Qureshi@csiro.au (M. Ejaz Qureshi), Stuart.Whitten@ csiro.au (S.M. Whitten), Mainuddin.Mohammed@csiro.au (M. Mainuddin) Steve.marvanek@csiro.au (S. Marvanek), A.Elmahdi@bom.gov.au (A. Elmahdi).
}

irrigation (CSIRO, 2008) indicating water overallocation in the MDB by about $40 \%$. Finally, environmental concerns have led to demand for greater environmental flows. These issues are driving debate about total water diversions and water set-aside for the environment (Kirby et al., 2012). Furthermore, irrigation faces changing world food markets, and rapidly evolving water policy reforms.

Design of effective and efficient government policies to help manage these water resources is limited by a paucity of information about the likely scale and scope of the impacts of continuing current management or alternative options. For example, there is evidence that water markets or trading in the southern MDB assisted some irrigators in avoiding substantial financial losses (Kirby et al., 2012; Mallawaarachchi and Foster, 2009; Oliver et al., 2009). In this paper we directly address the question of relative benefits of different policy mechanisms including water markets and trading.

Integrated biophysical and economic modelling is becoming a common approach for assessing policy scenarios across watersheds or other scales (Jakeman and Letcher, 2003). The approach has gained momentum with the introduction of integrated 
catchment management policies (MDBC, 2001) and legal requirements for water resources management in the MDB. Attempting to carry out an integrated assessment is a major challenge because the approach requires establishing links between different disciplines and utilising biophysical and economic data often collected at different scales and time periods.

Mathematical programming models have been used to link biophysical and economic information in an integrated biophysical and economic modelling framework and to assess impacts of agricultural policies and scenarios. These models are widely used to analyse irrigation water demand and agricultural-environmental policies since these models work well with a multitude of resource constraints and complex interaction between agriculture and the environment (Griffin, 2006). These models are also accepted for analysing the impact of climate change and water resources management policies and scenarios (Adamson et al., 2009; Qureshi et al., 2007, 2010). However, these models have a tendency towards overspecialisation in production and resource allocation (Howitt et al., 2010; Howitt, 1995). Often, maximum or minimum resource constraints were added to address the issue of overspecialisation (Qureshi et al., 2007).

Different methods have been developed to solve the aggregation and overspecialisation problem in agriculture production models. Positive Mathematical Programming or PMP has been suggested to deal with the problem of aggregation and specialisation in mathematical programming models (Howitt, 1995). The PMP approach has been widely used in agriculture production models due to its many advantages compared to conventional mathematical programming or traditional optimisation models, including an exact representation of the reference situation or observed value of production, lower data requirements, and continuous changes in model results in response to continuous changes in exogenous variables (Röhm and Dabbert, 2003). In recent years, PMP has also become a widely accepted method for analysing water demand as these models work well with the multitude of resource, policy, scenario, and environmental constraints often observed in practice (Griffin, 2006; Howitt et al., 2010).

The term 'positive' in a PMP model implies the use of observed data as part of the model calibration process. The approach uses a three-step procedure in which a non-linear cost function is calibrated to observed land use of each agricultural activity across catchments (Howitt et al., 2010). The first step in PMP is a nonlinear program model of farm profit maximisation with calibration constraints set to observed values of land use. The Lagrangian multiplier on the calibration constraints is used in the second step to parameterise a quadratic PMP cost function. The third step is a non-linear objective function that includes the PMP cost function restrictions on a resource. At this stage, the program completely self-calibrates and calculates all of the necessary parameters and is used for policy or scenario analyses by incorporating additional policy or scenario constraints and re-running.

Calibration in PMP models has been reviewed and critiqued in the literature (Chen and Onal, 2012; Heckelei and Wolff, 2003) and variations have been developed including a generalised maximum entropy or GME (Heckelei and Britz, 2005; Paris and Howitt, 1998). However, the GME procedure has seen little application in applied research. Along with other reasons, one of the reason of its limited application is the limited availability and/or reliability of the required information (Merel and Bucaram, 2010). McCarl (1982) suggested an alternative top-down approach by restricting the choice on crop mix to a convex combination of historical crop mixes. However, the approach requires substantive additional data at several scales which may not be available. The approach also requires arbitrary adjustments to the model specifications which could be difficult to check easily.
Integrated biophysical and economic models have evolved parallel to research on improving PMP models for water policy simulation analysis. Economic models generally lack detailed representation of hydrology while the hydrology models lack the ability to allocate water in an economically efficient manner. Hybrid hydro-economic models, either holistic or compartmental, have been built (Cai, 2008). Compartmental hydro-economic models often composed of a hydrologic model linked with an economic model calibrated using the PMP approach (Gomann et al., 2005; Quinn et al., 2004). However, we are not aware of any irrigated agriculture economic impact PMP study where the model included all the major climate related impacts, including impact on water allocations, crop effective rainfall, crop evapotranspiration and water requirement and impact on irrigation water quality. As we demonstrate, these factors can have an important influence on the model results.

This paper develops an irrigation sector integrated biophysical and economic model utilising the PMP modelling approach. The model is used to assess the impacts of climate change scenarios and water allocation policies on the profitability of major irrigation activities in catchments of the southern Murray-Darling Basin, Australia. The methodology used, the key steps taken in obtaining and linking the biophysical and economic data, and the challenges and difficulties faced in constructing a baseline condition (or base case model scenario) are described in the next section. This is followed by a section on model calibration and its reliability as an analytical model for economic analysis. Results and discussion are presented in the fourth section. Conclusions and policy implications complete the paper.

\section{Methodology and data acquisition procedures}

\subsection{Model focus, data acquisition and scaling issues}

We focus on the southern Murray-Darling Basin (MDB), Australia (shown in Fig. 1). The MDB is Australia's most significant river system and accounted for more than $50 \%$ of Australia's total water consumption (more than $80 \%$ used by the irrigation sector), mostly in the southern MDB, and in total contributes around $40 \%$ of Australia's gross value of agricultural production (ABS, 2011).

The CSIRO carried out a detailed basin scale assessment of the anticipated impacts of climate change on the availability and use of water resources in the MDB (CSIRO, 2008). The four scenarios CSIRO considered were: a) base case scenario of historical development and historical climate; b) historical development and a future climate change dry scenario; c) historical development and a future climate change median scenario; and d) historical development and a future climate change wet scenario. Details of these scenarios, including data, methods, and the models used can be found in the CSIRO Sustainable Yield project reports (CSIRO, 2008).

The choice of an appropriate scale for an integrated biophysical and economic model is important because mechanisms vital to the spatial dynamics of a process at one scale may be unimportant or inappropriate to another. We consider the subcatchment level to be the most appropriate scale because most sub-catchments are small enough to limit climate and crop variation and have relatively uniform rules governing entitlements and allocations [for detail on MDB water entitlements and allocations see Kaczan et al. (2011)], but are large enough to minimise the total data requirement and for aggregated economic analysis. ${ }^{1}$ The CSIRO study subcatchments were not aligned with the natural resources management planning (NRM) regions or Statistical Local Areas (SLAs) scale reported by the Australian Bureau of Statistics (ABS) in AgStats for agricultural land and water use and gross values data and economic performance. Land use data were obtained from the ABS. These data were collected at Statistical Local Area (or SLA) level and were

\footnotetext{
${ }^{1}$ In Australia, water is allocated to individual irrigation districts, valleys or regions based on their historical water rights or entitlements (with associated securities) linked to the historical land use along with dam storage capacity and current year rainfall. However, these water entitlement and allocation rules differ depending on state or territory. In South Australia and Victoria, irrigation water entitlements are more secure (or high security) than in NSW where the irrigators have less secure (or general security) entitlements. This was the reason that the water allocations in Murray NSW (for example) were close to zero in 2007-08 when there was severe drought while water allocations were high in SA and Vic in the same year (Kaczan et al., 2011).
} 


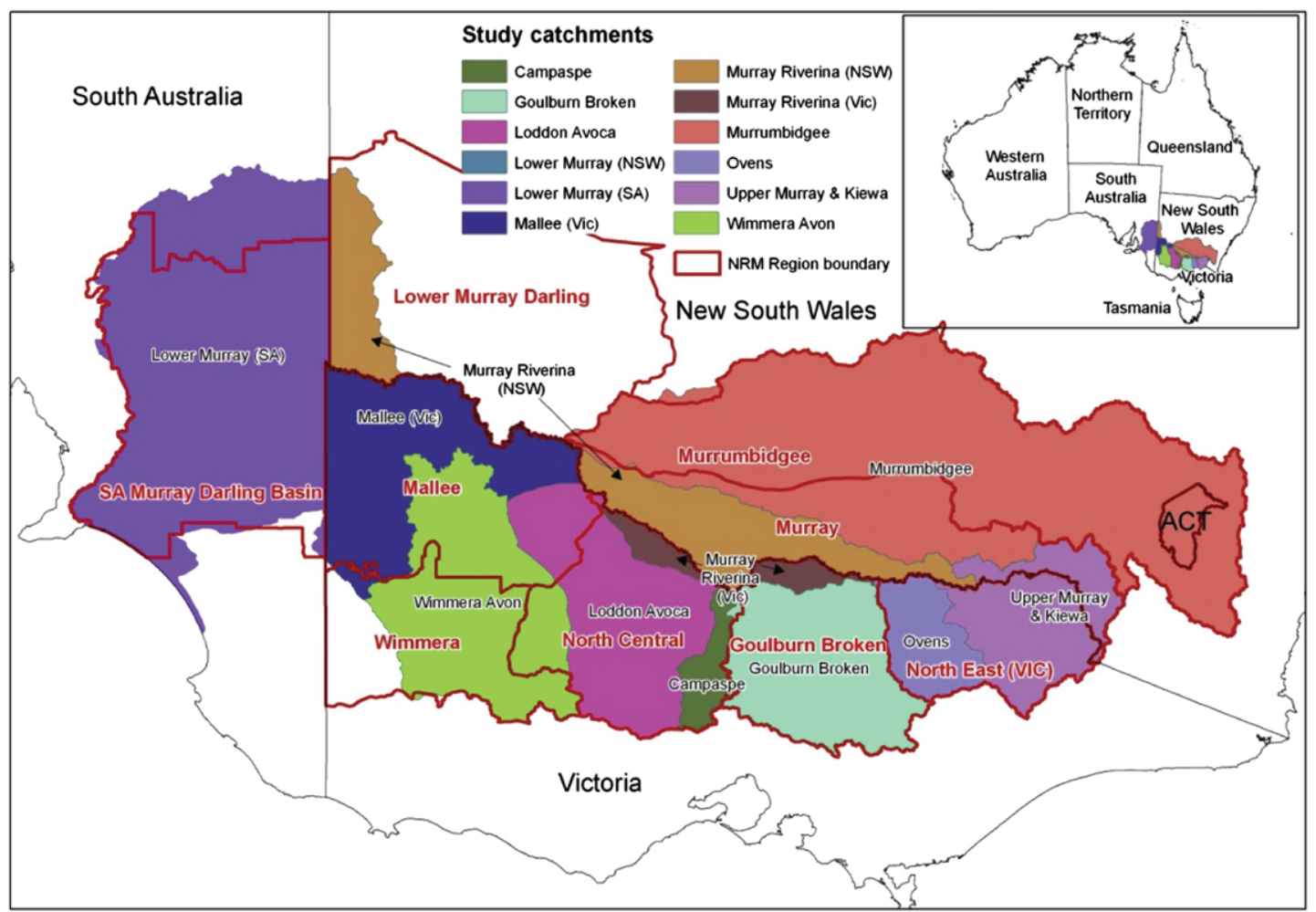

Fig. 1. Map of the Murray-Darling Basin southern catchments.

disaggregated across watershed (here after called catchments) boundaries in order to estimate the agricultural activity occurring within the reporting catchments. The linking and alignment process resulted in agricultural land use area for 13 catchments. Later, the Lower Murray-Darling part of NSW was combined with Murray Riverina NSW catchment for simplicity (due to its very small land and water use) resulting in 12 catchments. A schematic representation of the steps involved in land use data scaling is shown in Fig. 2. A detail on the steps involved in land use scaling is provided in Appendix A.

Simulated irrigation water diversion data for 111 years estimated for CSIRO Sustainable Yield project (CSIRO, 2008) was adjusted to the case study catchments for the four climate scenarios. ${ }^{2}$ To represent the high degree of variability in Australian climate and the resulting variability in historical water allocations (supply), we organised the water diversion data of the four climate scenarios in ascending order and classified them into four distinct categories or, states of nature (i.e. very dry, dry, wet and very wet). A very dry state of nature represents the mean of the $12 \%$ of driest years, a dry state of nature represents the mean of the next $38 \%$ of dry years, a wet state of nature represents the mean of the next $38 \%$ of relatively wet years, and a very wet state of nature represents the mean of the $12 \%$ of the wettest years in the 111 year simulation. This gave a final set of 16 (i.e. 4 scenarios $\times 4$ states of nature) different potential states of nature according to climate change and long-run variability in rainfall. For example, low water allocation years become more common as the climate moves from no change to severe change.

Despite the alignment effort there was a mismatch between irrigated land use and simulated water diverted in most catchments due to an under/overestimation of land use or water diversion data calculated for each catchment (i.e. inclusion and exclusion of more spatial area) or due to not accounting for groundwater use. For example, in Loddon-Avoca, water use in 2005-06 (considered a long term average year) was about $5 \%$ of the SMDB while the water allocation under the climate base case was close to $10 \%$ of the total water allocated for the SMDB. On the contrary, in Murray Riverina Vic, water use in 2005-06 was about $20 \%$ of the total water use in the SMDB while the water allocation under the climate base case was less than $15 \%$ We aligned land use data with regional base case (or initial) water allocations data by accounting for expected mean crop evapotranspiration (ET), expected mean effective rainfall, individual on-farm crop irrigation efficiency and estimated net

${ }^{2}$ These are the years for which the hydrology (including rainfall record) was available for MDB. irrigation requirements. We redistributed and allocated water to each region by multiplying the proportion of total water use by total water available for irrigation in each of the four climate scenarios. This approach of allocating water to individual crops and catchments is consistent with previous studies where water demand is calculated according to irrigation water requirements and adjusting for average estimated irrigation efficiencies and average crop effective rainfall (George et al., 2011a,b).

Agricultural productivity of water is impacted by its salt content which in turn is impacted by climate change. The CSIRO (2008) study did not provide any data about the impact of climate change on water salinity. We used MDB MSM-BIGMOD, a suite of software packages (MDBC, 2002) and estimated salinity in the River Murray across catchments (except Murrumbidgee catchment as MSM-BIGMOD only accounts for Murray River catchments) in the southern MDB. MSM-BIGMOD simulates the Murray River system by dividing it into a number of river reaches. The salinity of the inlet channel is dependent on the history of flow. The model maintains a salt balance even when a reach ceases to flow and the dead storage evaporates. Estimating weekly/monthly/annual river salinity under the different climatic conditions is described by Elmahdi et al. (2008). This procedure resulted in salinity $^{3}$ data for 25 years (i.e. 1975-2000) at different reaches across the Murray catchments for different scenarios. An average of salinity data at different reaches is used for those catchments which received water from more than one reach. These data were ranked in ascending order and assigned to our four states of nature (i.e. more salinity in dry years and less in wet years) within each climate scenario. Murrumbidgee predicted salinity concentration is taken from Beale et al. (2000) with change in salinity concentration guided by the Murray catchment analysis (i.e. $20 \%$ average increase in salinity in all Murray catchments in a year resulted in a $20 \%$ increase in Murrumbidgee).

Along with reduced rainfall and water allocations, climate change is expected to increase crop water requirements by increasing evapotranspiration. On the contrary, higher concentration of $\mathrm{CO}_{2}$ may lead to enhanced plant growth through a range of effects (Drake et al., 1997) and could affect crop yield or reduce crop water requirement. However, given the lack of decisive information about the likely impacts for the crops grown in the MDB this aspect is not considered in this analysis. Instead, we have estimated actual crop ET, effective rainfall and net irrigation requirements of different crops grown in the southern MDB using a soil water

${ }^{3}$ Electrical Conductivity (EC) measured in micro-Siemens/cm where $1 \mu \mathrm{S} /$ $\mathrm{cm}=1 \mu \mathrm{mho} / \mathrm{cm}$ 


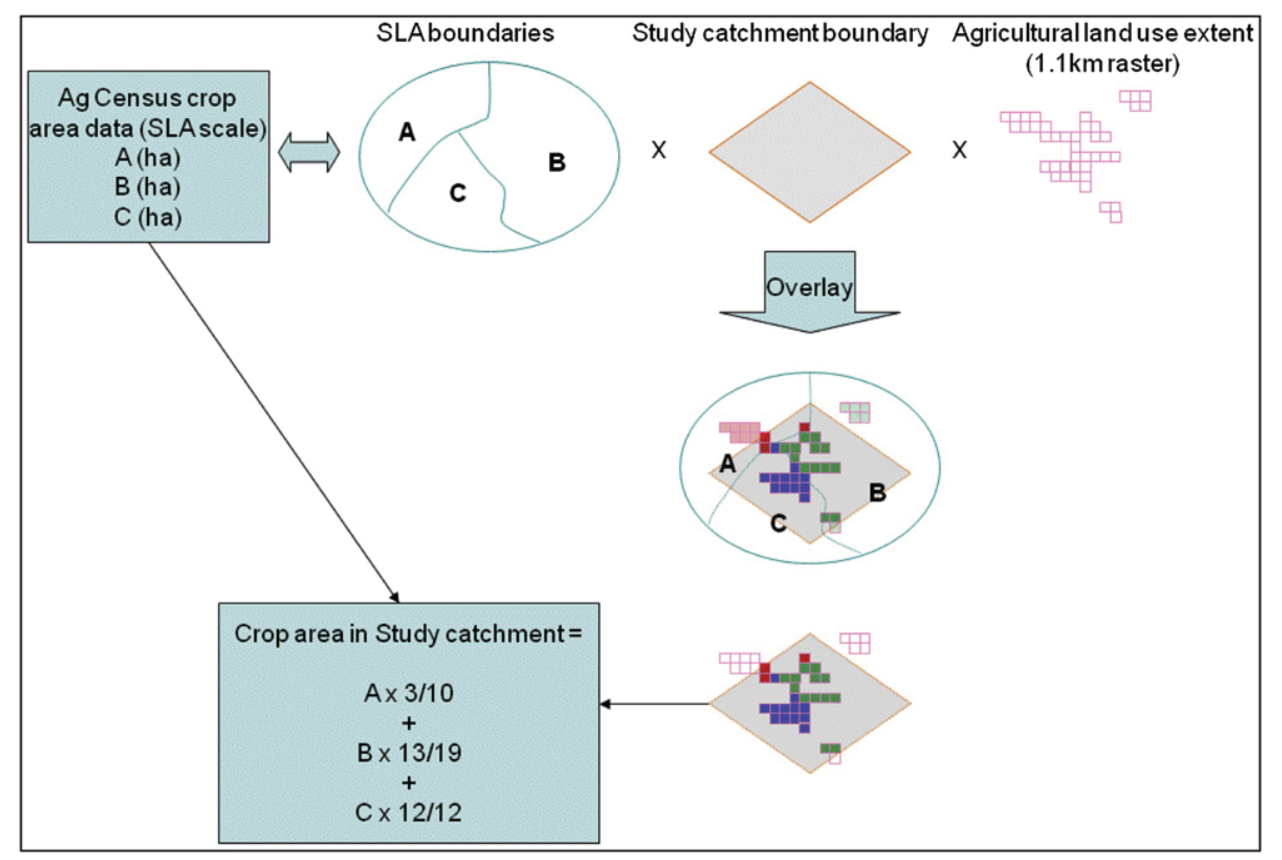

Fig. 2. A schematic representation of the steps involved in land use data scaling in southern MDB.

balance simulation model. The model is similar to that of the CROPWAT model developed by FAO (Allen et al., 1998). The model has been used previously to estimate ET and irrigation water requirements for a range of crops grown in the MDB (Mainuddin and Kirby, 2009; Qureshi et al., 2007). We used spatial average historical and future climate scenario rainfall and potential ET data available from the MDB sustainable yield study (Chiew et al., 2008). Maximum crop water requirements (in millimetres) for each of the eight major agricultural activities are estimated for each scenario and state of nature to use in the analysis. The detail of the data including ET and effective rainfall under each scenario and state of nature and potential maximum crop yield is given in Qureshi et al. (2012).

The key economic data are commodity and input prices. To deal with temporal variation in commodity prices, average recent prices of individual commodities were obtained from ABARE and ABS and other publications (ABARE, 2007; ABS, 2006) as well as from state agricultural departments. For simplicity in the reported analysis water costs are limited to an average per mega-litre water pumping charge.

\subsection{Model objective function and constraints}

Mathematical description of the model including objective function and constraints is given in (Qureshi et al., 2012). A summary of the model is as follows while a brief mathematical description of the model is provided in Appendix B. The objective of the model is to maximise profits for each catchment (region) after accounting for amortised annual establishment costs and operating/variable costs subject to water and land availability constraints. The water availability constraint in the model ensures that for each scenario and state of nature, the sum of the amount of water required will not exceed the total amount of water available after accounting for conveyance losses in each region. The land availability constraint ensures that for each region, the sum of the land areas required will not exceed the total available area for irrigation in a region. Inclusion of a crop water production function allows modelling of deficit irrigation. That is applying less than the full crop water requirement and accepting less than the greatest possible yield. By reducing the water use per hectare, a greater area can be irrigated. However, the potential for deficit irrigation depends on the type of crops. Thus, the current model allows deficit irrigation subject to a certain threshold of minimum water requirements for each agricultural activity. The amount of irrigation water use required to meet a specific crop's ET depends on the effective rainfall and the on-farm irrigation efficiency. The irrigation water salinity can affect crop productivity and requires additional water to maintain crop productivity. As such, the model allows for this increase in irrigation requirements.

Later in the analysis, the model is run with the option of water trade so as to evaluate the impact of water trading, especially as water availability changes. For the trading purpose, the water constraint presented is modified to allow feasible trades of water among regions across the basin. Trading equates the value of marginal product to the shadow price of the water and results in optimal allocation across the regions. Those regions which are not part of the surface water regulated system and/or have no physical linkage with other catchments are excluded from the interregional water trading market. ${ }^{4}$

\subsection{Model calibration}

Calibration of a model using land and water use data to observed values was necessary to ensure it was able to adequately represent real world responses and to address the problem of overspecialisation in agricultural production (Howitt et al., 2010; Howitt, 2005). The positive mathematical programming or PMP approach has been used to calibrate the model and address the problem of overspecialisation assuming a profit-maximising equilibrium in the reference period and adding a cost function. However, calibration in PMP models has been critiqued in the literature (Heckelei and Wolff, 2003) and variations have been proposed including a generalised maximum entropy or GME (Heckelei and Britz, 2005; Paris and Howitt, 1998). However, the GME procedure has seen little application in applied research and one of the reasons of its limited application is the limited availability and/or reliability of the required information (Merel and Bucaram, 2010). An alternate top-down approach suggested by McCarl (1982) could be used by restricting the choice on crop mix to a convex combination of historical crop mixes. However, the top-down approach requires substantive additional data at several scales and arbitrary adjustments to the model specifications would be difficult to check easily.

We applied a variant of PMP developed by Röhm and Dabbert (2003) that accounts for the greater elasticity of substitution amongst crop variants than amongst completely different crops. In the current analysis, the variants include the same crop grown with different water application rates and accounting for individual crop deficit irrigation. A simple example showing how coefficients of the cost functions are estimated in PMP approach and used in a non constrained mathematical programming model is given in Qureshi et al. (2012).

PMP model self-calibrate to the reference year data, calculates the necessary parameters and can be used for policy or scenario analysis by incorporating relevant parameter constraints and re-running. Typical output of the model includes revenues by crop and catchment, land use, water use, crop ET rate, and marginal value of water. Each crop within each catchment is assigned a specific on-farm irrigation system and viewed as a representative farmer. This level of aggregation is useful for specifying disaggregated biophysical and other resource constraints, and allows for more accurate climate impact scenarios and water policy options modelling. All the

\footnotetext{
${ }^{4}$ As trade already occurs across feasible regions we assume that the required infrastructure is available, however we acknowledge that further investment could be required to overcome some transfer impediments such as capacity constraints. Within the model limits to water trading can be applied to prevent greater trade in the light of farm expansion capacity, use of a minimum volume of water on-farm demand constraint, or to represent regional administrative rules and regulations on water trading.
} 
hydrologic, agronomic and economic data were linked in GAMS (General Algebraic Modelling System) (Brooke et al., 2004).

We compared model runs with land and water use data from other years and the results were broadly consistent for all the catchments and agricultural activities, shown in Tables 1 and 2 and Figs. 3 and 4. While PMP conclusions can be weaker the further from the calibration space, in the short run they are reasonably robust and broadly consistent with the observed responses.

\section{Results and discussion}

In the analysis and comparisons that follow we present a summary of the results from different climate change scenarios. Instead of presenting the impact of each state of nature within a scenario, we present expected mean value (i.e. multiplication of values in each state by its attached probability and summation of the four states) for the three scenarios (dry, medium and wet) and compare against a baseline case, for three treatments (here after called Policy 1, Policy 2 and Policy 3). The baseline case includes water allocations and crop effective rainfall as well as crop ET and water salinity levels based on CSIRO climate change base case scenario high state of nature which we assume represents a long term average rainfall and water allocation year. Policy 1 - Most restricted module presents impact of climate change scenarios when the irrigators face reduction in water allocations, and crop effective rainfall, an increase in crop ET and water salinity, and have no cropmanagement adaptation and no interregional institutional (i.e. water market) flexibility. Policy 2 - Less restricted with farm adaptation flexibility module relaxes the on-farm management options available to include deficit irrigation. Policy 3 - Most flexible with farm adaptation and interregional water trading module allows interregional water markets where irrigators can buy and sell from

Table 1

Southern MDB catchments irrigated area (1000 ha) and water use (GL) - ABS 20056 observed versus model simulated.

\begin{tabular}{lcccc}
\hline & ABS & Model & ABS & Model \\
& $2005-06$ & $\begin{array}{l}\text { simulated } \\
\text { land use }\end{array}$ & $\begin{array}{l}\text { 2005-06 } \\
\text { land use }\end{array}$ & $\begin{array}{l}\text { simulated } \\
\text { water use }\end{array}$ \\
\hline Murrumbidgee & 298 & 288 & 1986 & 1986 \\
Ovens & 6 & 6 & 29 & 27 \\
Goulburn-Broken & 160 & 160 & 1007 & 977 \\
Campaspe & 26 & 26 & 195 & 192 \\
Lodon-Avoca & 115 & 115 & 923 & 923 \\
Wimmera-Avon & 18 & 17 & 132 & 132 \\
Upper Murray & 20 & 20 & 95 & 87 \\
$\quad$ and Kiewa & & & & \\
Murray Riverina NSW & 134 & 131 & 1236 & 1236 \\
Murray Riverina Vic & 38 & 38 & 379 & 379 \\
Mallee Vic & 36 & 32 & 249 & 249 \\
Lower Murray SA & 62 & 58 & 479 & 479 \\
Total & 913 & 891 & 6710 & 6667 \\
\hline
\end{tabular}

Table 2

Agricultural activities in SMDB catchments irrigation area (1000 ha) and water use (GL) - ABS 2005-6 observed versus model simulated.

\begin{tabular}{lcccc}
\hline & $\begin{array}{l}\text { ABS 2005-06 } \\
\text { land use }\end{array}$ & $\begin{array}{l}\text { Model } \\
\text { simulated } \\
\text { land use }\end{array}$ & $\begin{array}{l}\text { ABS 2005-06 } \\
\text { water use }\end{array}$ & $\begin{array}{l}\text { Model } \\
\text { simulated } \\
\text { water use }\end{array}$ \\
\hline Cereals & 181 & 181 & 454 & 468 \\
Rice & 92 & 80 & 1107 & 1111 \\
Dairy & 498 & 490 & 4305 & 4132 \\
Fruits and & 67 & 66 & 444 & 550 \\
$\quad$ vegetables & & & & 404 \\
Grapes & 76 & 76 & 398 & 6665 \\
Total $^{a}$ & 914 & 893 & 6708 & \\
\hline
\end{tabular}

Note: Dairy represents all the pasture related activities.

a There is a small rounding error which makes the difference in total areas, especially the area of fruits and vegetables once the areas of the individual activities are combined.

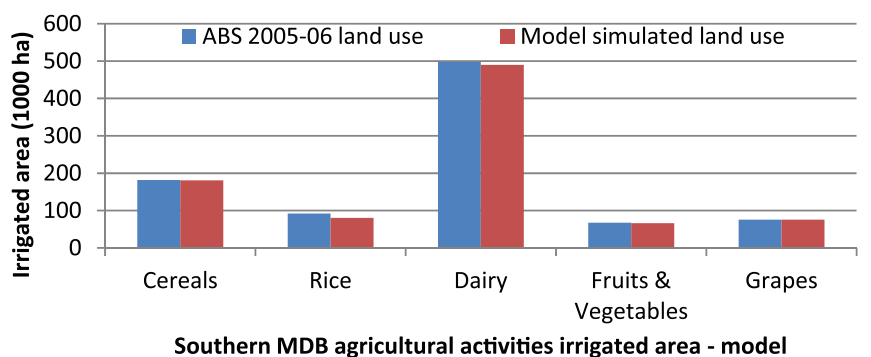

simulated versus ABS 2005-06 observed

Fig. 3. Model simulated and ABS observed land use by activities in the SMDB.

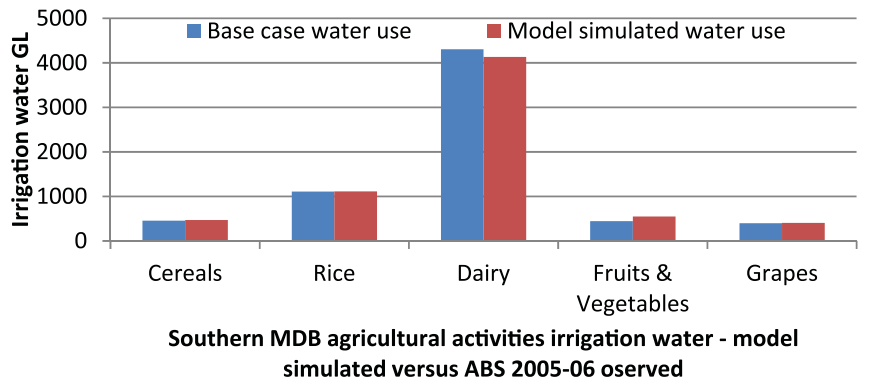

Fig. 4. CSIRO base case and model simulated water use by activities in the SMDB.

irrigators in other regions. Effectively the model is run across the 12 sub-catchments, four climate scenarios, four states of nature and three policies - i.e. a total of 48 runs.

Fig. 5 and Table 3 show a set of aggregate gross values of the baseline case and expected mean values of climate dry, climate medium and climate wet scenarios. Table 3 also shows percentage change in gross values from the baseline case. These estimates show the degree of variability in gross values under different alternative climate scenarios compared to the baseline case. The reduction in economic returns is obvious, especially in climate dry scenario (36\%). Fig. 5 and Table 3 also show how onfarm adaptation options and water markets can mitigate these losses in Policies 2 and 3, respectively. However, as shown in Fig. 5, there is very little difference in the estimates of the gross values for Policies 1 and 2. This implies that the on-farm adaptation value of deficit irrigation is negligible, reducing losses to gross values by just one percentage point at most. However, comparison of Policy 2 and 3 results leads us to conclude that reductions in gross value are markedly smaller when irrigators are able to take advantage of full adaptation possibilities in Policy 3 via interregional water markets. Under the climate dry scenario water markets are able to reduce loss of gross value to $14 \%$ (i.e. a reduction of $12 \%$ from the inflexible Policy 1 ). Fig. 6 shows about $2 / 3$ rd reduction in gross values under the extreme case (i.e. very low state of nature of climate dry

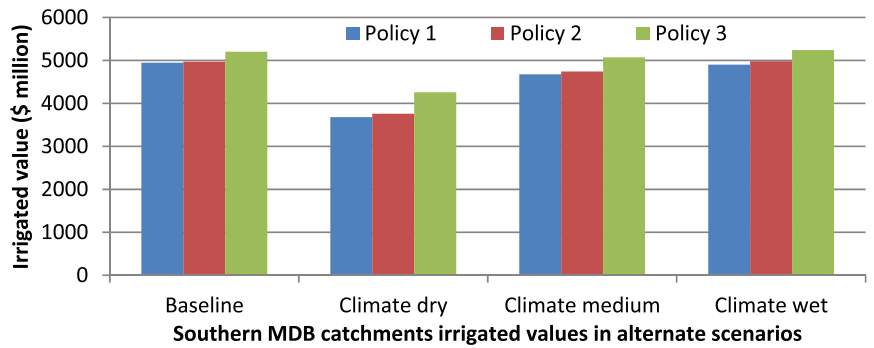

Fig. 5. Aggregate expected mean gross values of the southern MDB under the baseline case and alternative scenarios for three policies. 
Table 3

Aggregate expected mean gross values of the southern MDB and percentage change from the baseline case in alternative scenarios for three policies.

\begin{tabular}{|c|c|c|c|c|c|c|}
\hline & Policy $1(\$)$ & Policy $2(\$)$ & Policy $3(\$)$ & Policy 1 (\%) & Policy 2 (\%) & Policy 3 (\%) \\
\hline Baseline case & 4944 & 4972 & 5201 & $\mathrm{~N} / \mathrm{A}$ & 1 & 2 \\
\hline Climate dry & 3678 & 3761 & 4260 & -36 & -34 & -26 \\
\hline Climate medium & 4678 & 4745 & 5070 & -18 & -17 & -12 \\
\hline Climate wet & 4904 & 4981 & 5240 & -14 & -13 & -9 \\
\hline
\end{tabular}

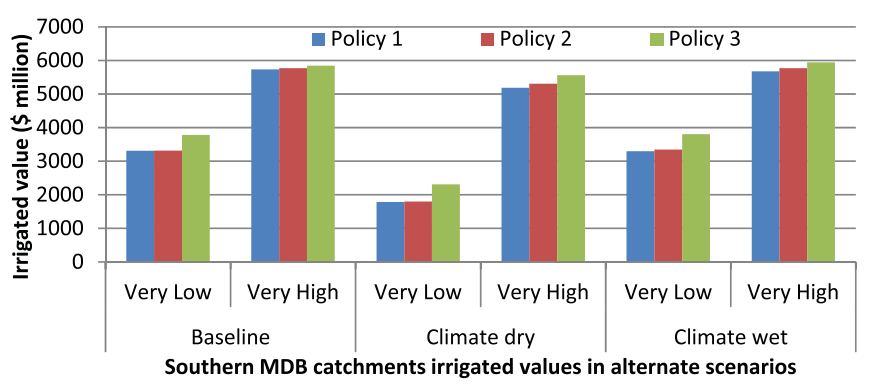

Fig. 6. Aggregate gross values of the southern MDB of very low and very high states of nature under the baseline case, climate dry and climate wet scenarios for three policies.

scenario), and a similar reduction in gross value losses is possible with Policy 3. Given the recent shifts in policy towards improving irrigation efficiency, we tested the impact of increased water use efficiency and found that adoption of the most efficient techniques with Policy 2 can reduce mean expected climate change impact by about $10 \%$. This illustrates that there may be greater on-farm adaptation available than our base model suggests. The results clearly indicate the impact of climate change and potential for this type of integrated biophysical and economic modelling for policy analysis.

\section{Conclusions}

The model described in this paper has been constructed with the objective of informing the water policy in the southern MDB in Australia. Several key steps were necessary to address data incompatibility, scaling and model calibration issues. For example, land use data had to be aligned with water allocation data in order to describe the economic returns from irrigation water use across catchments and to examine the impact of reduced water allocations. The PMP approach has the advantage of calibrating exactly to the base year of observed land use data which increases accuracy within the program. The results presented in this paper suggest the usefulness of integrated environmental and economic PMP modelling for such policy analysis. Accurate assessment of a region's allocation can help governments in evaluating climate change impacts, impacts of allocation changes (such as to the environment or urban consumers) and in developing and implementing policy such as regional water sharing plans.

While the model presented has several features which improve and distinguish it from previous work, such as inclusion of deficit irrigation, effective rainfall and evapotranspiration effects, there remain a number of further opportunities for development. We suggest that future work focus on greater biophysical modelling accuracy including water allocations based on more detailed assessment of regional rainfall and run off. Potential impact on $\mathrm{CO}_{2}$ and crop yield could be investigated along with potential for crop range shifts or new crops made possible by a changing climate. Another policy opportunity is examination of the impact of economic incentives such as subsidies for irrigation water efficiency as well as a wider range of alternative policy frameworks than examined in the current model. Finally, the model is relatively deterministic with no direct accounting for risk and uncertainty associated with key economic parameters, such as commodity prices and profit range distributions. Inclusion of a more sophisticated understanding of these factors will allow for the assessment of the sensitivity of individual crops and regional economies to future economic and climatic conditions.

\section{Acknowledgements}

This paper was produced as part of the CSIRO Flagship Program 'Water for a Healthy Country' and the Land and Water Australia Innovation Funding. The authors wish to thank Jeff Connor, Kurt Schwabe and Brad Franklin for very useful discussion on mathematical modelling in general and on PMP in particular and the helpful comments of three anonymous reviewers.

\section{Appendix A. Steps involved in land use data scaling}

The Bureau of Rural Sciences (BRS) land use grid (BRS, 2004) was used to determine what proportion of a broad land use category occurring in a given SLA fell into a given reporting catchment. Eight agricultural activities dominate in the southern MDB [including cereals, rice, pasture related activities (represented by dairy), vegetables (represented by potatoes), citrus fruits, deciduous fruits, stone fruits and grapes] are considered in the analysis. Agricultural commodities in the ABS data were categorised according to the SPREAD land use categories represented in the BRS land use grid. For specific tree crops (fruits), AgStats reports tree numbers rather than area in hectares. For disaggregation and scaling, tree numbers were converted to hectares based on the orchard tree density estimates used in the 2001 National Land and Water Resources Audit. The commodity level tree crop areas derived from tree numbers were cross checked with the ABS aggregate areal statistics for tree crops where available. Similar issues were faced in livestock area data. The ABS does not provide livestock areas; rather the number of dairy, and beef cattle and sheep per SLA along with total grazing land. The BRS land use grid does not specify livestock types. We disaggregated total grazing land within an SLA to area of dairy and beef cattle and sheep pastures based on Dry Sheep Equivalent (DSE) proportions of livestock numbers reported in the SLA (DSE is a commonly used procedure in assessing livestock production and its economic productivity). The derived SLA based livestock areas were distributed to catchments using the SPREAD pasture category following the above procedure. This procedure results in the agricultural land use area by crop or livestock type for each catchment. Due to commercial sensitivity, ABS does not provide irrigated area by commodity type but rather irrigated areas of aggregate land use classes at a small scale within an NRM region. We used our spatial disaggregation method and estimated the irrigated area of commodities for each catchment. 


\section{Appendix B. Mathematical description of the biophysical and economic model component}

The analytical framework or methodology used in this analysis extends the previous mathematical modelling approaches (ABARE-BRS, 2010; Adamson et al., 2009; Grafton and Jiang, 2011; Hafi et al., 2009; Qureshi et al., 2007). The model explicitly considers several climate induced water resource impacts and adaptation options in the southern MDB. It is anticipated that the combined impact of climate change (including impact on water allocation, rainfall, crop ET and salinity) on irrigated agriculture may be greater than assessed in the previous studies. However, adaptation options and institutional policies generate the opposite effect by ameliorating the impacts of reduced water availability. The aim of this model was to yield a more thorough understanding of the differential impacts and inform resource managers and policy makers for a more sound policy response.

\section{B.1. Irrigation sector impacts of climate change}

The objective function of the model is to maximise profits $\pi$ under each scenario and state of nature for the MDB after accounting for amortised annual establishment costs and operating or variable costs subject to available land and water. The objective function is expressed in Eq. (1). All of the variables and parameters used in Eq. (1) and subsequent equations of the model are defined in Table 1. The first expression in Eq. (1) characterises the long-run on-farm irrigation and agricultural activity infrastructure capital investment choices that can vary across but not within a growing season. The second two expressions characterise the short run decisions that can be varied within a season after stochastically determined factors affecting production are revealed.

$$
\begin{aligned}
\Pi= & -\sum_{j} \sum_{h}\left(\text { IECost }_{j h}+\text { CECost }_{j}\right) \times \text { AREA }_{s r j h}-\sum_{s} \text { Prob }_{s} \\
& \times\left(\sum_{j} \sum_{h}\left(\text { VCost }_{r j}+\left(\text { WCharge }_{r} \times \mathrm{IW}_{s r j h}^{R}\right)\right) \times \text { AREA }_{s r j h}\right) \\
& +\sum_{s} \text { Prob }_{s} \times\left(\sum_{j} \sum_{h} \text { CPrice }_{r j} \times \text { YIELD }_{s r j h} \times \text { AREA }_{s r j h}\right)
\end{aligned}
$$

The water availability constraint is given in Eq. (2) and a land availability constraint in Eq. (3). The water availability constraint ensures that for each state of nature $s$ and region $r$, the sum of the amount of water required will not exceed the total amount of water available ( TWat $_{s r}$ ) after accounting for conveyance losses (CLoss $r$ ) in each catchment. The land availability constraint ensures that for each region $r$, the sum of the land areas required will not exceed the total available area for irrigation $\left(\mathrm{TArea}_{r}\right)$ in a catchment.

$$
\begin{aligned}
& \sum_{j} \sum_{h} \mathrm{IW}_{s r j h}^{C} \times \text { AREA }_{s r j h} \leq\left(1-\text { CLoss }_{r}\right) \times \text { TWat }_{s r} \quad \forall s, r \\
& \sum_{j} \sum_{h} \text { AREA }_{s r j h} \leq \text { TArea }_{r} \quad \forall r, s
\end{aligned}
$$

The portion of the total available area not irrigated is considered dryland and represented by Eq. (4). The dryland constraint is used to release irrigated land towards dryland activities if it is not economic to irrigate given water allocation and market conditions.
DAREA $_{r}=$ TArea $_{r}-\sum_{j} \sum_{h}$ AREA $_{s r j h} \quad \forall r, s$

Table 1A

Parameters used in the model and their explanation.

$s$, each state of nature reflecting very low, low, high and very high rainfall and water allocations; $r$, irrigation catchment or region (12 catchments of the southern MDB); $j$, irrigated cropping activity (rice, cereals, vegetables, and fruit); $h$, on-farm irrigation efficiency system; AREA ${ }_{s r j h}$, irrigated area (ha); YIELD srjh $_{\text {, }}$ crop yield (t/ha); $\mathrm{ET}_{s r j h}^{R}$, crop water requirement $(\mathrm{mm})$; $\mathrm{ERain}_{\mathrm{srj}}$, regional crop effective rainfall; $a_{r j}$, intercept of the yield response function ( $\mathrm{t} / \mathrm{ha}$ or $\mathrm{l} / \mathrm{ha}$ ); $b_{r j}$, slope coefficient of the yield response functions $(\mathrm{t} / \mathrm{ml}$ or $\mathrm{l} / \mathrm{ml}) ; c_{r j}$, other (quadratic) coefficient of yield response function ( $\mathrm{t} \mathrm{ha} / \mathrm{ml}^{2}$ or $1 \mathrm{ha} / \mathrm{ml}$ ); $\operatorname{IEff}_{r j h}$, onfarm crop irrigation system efficiency; TWat $_{s r}$, total amount of water available after accounting for conveyance losses in each region; CLoss $_{r}$, water conveyance losses in each region; $\mathrm{IW}_{s r j h}^{R}$, irrigation water use (ml/ha) for revenue purpose; $\mathrm{IW}_{s r i h}^{\mathrm{C}}$, irrigation water use ( $\mathrm{ml} / \mathrm{ha}$ ) after accounting for leaching for cost purpose; IECost ${ }_{j h}$, irrigation establishment cost (\$/ha); CECost ${ }_{j}$, crop establishment cost (\$/ha); Probs, probability (prop) of water allocations/supply; CPrice $_{r j}$, crop price (\$/ha); DRevenue, dry revenue (\$/ha); VCost $_{r j}$, variable cost (\$/ha) of each agricultural activity; WCharge $_{r}$, water charges or price of water $(\$ / \mathrm{ml})$; YldMax $\mathrm{x}_{s p h}$, maximum crop yield ( $\left.\mathrm{t} / \mathrm{ha}\right)$; WAllocation $_{s r}$, the fraction of an irrigator's entitlement; WPrice ${ }_{s r}$, water market price $(\$ / \mathrm{ml})$; $\mathrm{TEC}_{s r}$, total electrical conductivity; $\mathrm{TH}_{1} \mathrm{TH}_{2}$, thresholds defined for total electrical conductivity by agricultural activity depending on salinity tolerance.

\section{B.2. Modelling crop yield response to water and deficit irrigation}

YIELD $_{\text {srjh }}$ is a function of crop ET $\mathrm{ET}_{\text {srjh }}^{R}$ which is crop water requirement including irrigation water use $\mathrm{IW}_{\text {srjh }}^{R}$ and effective rainfall $\left(\right.$ ERain $\left._{s r j}\right)$ and accounting for on-farm irrigation system efficiency $\left(\mathrm{IEff}_{r j h}\right)$. A quadratic yield response function is used of the form:

$\mathrm{YIELD}_{s r j h}=f\left(\mathrm{ET}_{s r j h}^{R}\right)=a_{r j}+b_{r j} \times \mathrm{ET}_{s r j h}^{R}+c_{r j} \times\left(\mathrm{ET}_{s r j h}^{R}\right)^{2}$

where: $a_{r j}$ is intercept of the yield response function ( $\mathrm{t} / \mathrm{ha}$ or $\mathrm{l} / \mathrm{ha}$ ); $b_{r j}$ is slope coefficient of the yield response functions ( $\mathrm{t} / \mathrm{ML}$ or $\mathrm{l} / \mathrm{ML}$ ); and, $c_{r j}$ is other (quadratic) coefficient of yield response function (t ha/ML ${ }^{2}$ or 1 ha/ML).

A minimum threshold is imposed on crop water requirement in those yield (production) functions where the intercept $a_{r j}$ is not zero to deal with negative yield occurrence at zero water usage. The amount of irrigation water use $\mathrm{IW}_{s r j h}^{R}$ required to meet a specific crop's $\mathrm{ET}_{s r j h}^{R}$ will depend on the $\mathrm{ERain}_{s r j}$ and the $\operatorname{IEff}_{r j h}$ as shown:

$\mathrm{IW}_{s r j h}^{R}=\left(\mathrm{ET}_{s r j h}^{R}-\mathrm{ERain}_{s r j}\right) / \mathrm{IEff}_{r j h}$

The irrigation water salinity can affect crop productivity and requires additional water to maintain crop productivity, as shown in Eq. (5b). ${ }^{5}$

$\mathrm{IW}_{s r j h}^{C}=\left(\mathrm{ET}_{s r j h}^{C}-\mathrm{ERain}_{s r j}\right) / \mathrm{IEff}_{r j h}$

\footnotetext{
${ }^{5}$ Irrigation water salinity is accounted for in the form of two components, i.e. concentration $\mathrm{SC}_{r}$ and electrical conductivity $\mathrm{EC}_{s r}$. The values of these two components result in total electrical conductivity $\mathrm{TEC}_{s r}$ (i.e. $\mathrm{TEC}_{s r}=\mathrm{SC}_{r}+\mathrm{EC}_{s r}$ ) of available water for each scenario and in each catchment/region.
} 
where $\mathrm{ET}_{s r j h}^{C}$ is the total crop water requirement which is greater than $\mathrm{ET}_{s r j h}^{R}$ (i.e. $\mathrm{ET}_{s r j h}^{C}>\mathrm{ET}_{s r j h}^{R}$ ) because of the salinity impact. It should be noted that $\mathrm{ET}_{s r j h}^{C}$ is used for cost purpose while yield is obtained using $\mathrm{ET}_{s r j h}^{R}$. Total irrigation water use is obtained following Kan et al. (2002) and Schwabe et al. (2006) as shown in Eq. (5c). These crop-water-salinity functions are in line with the literature on yield-water-salinity relationships (Letey et al., 1985) and research on the economics of salinity management (Schwabe et al., 2006).

$$
\begin{aligned}
\sum_{r} \sum_{j} \sum_{h} \mathrm{IW}_{s r j h}^{C} \times \mathrm{AREA}_{s r j h} & \leq \sum_{r}\left(1-\text { CLoss }_{r}\right) \times \text { TWat }_{s r} \forall s \\
-\sum_{s} \text { Prob }_{s} \times \text { WPrice }_{s r} \times & \left(\sum_{j} \sum_{h} \mathrm{IW}_{s r j h}^{C} \times \text { AREA }_{s r j h}\right. \\
& \left.- \text { WAllocation }_{s r}\right)
\end{aligned}
$$

$$
\mathrm{ET}_{s r j h}^{C}= \begin{cases}\left(x_{1}+\gamma_{1} \times \mathrm{TEC}_{s r} / \mathrm{TH}_{1}\right) \times \mathrm{ET}_{s r j h}^{R} & \text { if } \mathrm{TEC}_{s r} \leq \mathrm{TH}_{1} \\ \left(x_{2}+\gamma_{2} \times\left(\mathrm{TEC}_{s r}-\mathrm{TH}_{1}\right) /\left(\mathrm{TH}_{2}-\mathrm{TH}_{1}\right)\right) \times \mathrm{ET}_{s r j h}^{R} & \text { if } \mathrm{TH}_{1} \leq \mathrm{TEC}_{s r} \leq \mathrm{TH}_{2} \\ \left(x_{3}+\gamma_{3} \times\left(\mathrm{TEC}_{s r}-\mathrm{TH}_{2}\right) /\left(\mathrm{TH}_{2}-\mathrm{TH}_{1}\right)\right) \times \mathrm{ET}_{s r j h}^{R} & \text { if } \mathrm{TEC}_{s r} \geq \mathrm{TH}_{2}\end{cases}
$$

where $x_{1}, x_{2}$ and $x_{3}$ are numbers (factors) and their values start from 1 (i.e. $x_{1}=1$ ) and increases with $\mathrm{TEC}_{s r} . \gamma_{1}, \gamma_{2}$ and $\gamma_{3}$ are proportions, which also increase as the value of $\mathrm{TEC}_{s r}$ increases. $\mathrm{TH}_{1}$ and $\mathrm{TH}_{2}$ are two thresholds defined for $\mathrm{TEC}_{s r}$ which vary across agricultural activities depending on the salinity water tolerance.

Inclusion of a crop water production function allows modelling of deficit irrigation or applying less than the full crop water requirement and accepting less than the greatest possible yield. By reducing the water use per hectare, a greater area can be irrigated. However, the level of deficit irrigation depends on the type of crops. In general, cereals and grapes are tolerant to water stress to some extent. Rice is sensitive to water stress particularly at the flowering and the second half of vegetative period (Doorenbos and Kassam, 1979). Thus, the current model allows deficit irrigation subject to a certain threshold of minimum water requirements for each agricultural activity, see for detail (Qureshi et al., 2012). The plausible on-farm irrigation efficiency systems included in the model and the assumed irrigation efficiency of each system are also shown in (Qureshi et al., 2012).

\section{B.3. Modelling water trade and water prices}

Later in the analysis, the model is run with a water trade policy so as to evaluate the value of water trading, especially as water availability changes. For the trading policy, the water constraint presented in Eq. (2) is modified to allow trade of water among regions across the basin, as shown in Eq. (6). Those regions which have no physical linkage with other catchments are excluded from the interregional water trading market. At the basin scale analysis, no water price is included as the value of water trades represents a transfer payment within the basin therefore does not impact on aggregate results. For convenience, we assume that there is no restriction on interregional water trading and zero transaction costs of trade. Therefore, the regional trading gains could be considered the maximum possible gains of water markets.

$$
\sum_{r} \sum_{j} \sum_{h} \mathrm{IW}_{s r j h}^{C} \times \mathrm{AREA}_{s r j h} \leq \sum_{r}\left(1-\text { CLoss }_{r}\right) \times \text { TWat }_{s r} \forall s
$$

To estimate the impact of water trading on each region's total gross value and profitability, Eq. (7a) is included in the objective function (Eq. (1)). While in Eq. (7b), the parameters WPrice sr $_{\text {r }}$ and WAllocation $_{\text {sr }}$ represent water market price $(\$ / M L)$ and water allocation (ML) for each catchment, respectively. When the term in bracket in Eq. (7b) is positive, water is brought into the region through water purchases. When negative, water is transferred out of the region through water sales.
The steps carried out in estimating regional water price and using as water revenue for the water selling regions and water cost for the water buying regions are described by Qureshi et al. (2012).

\section{References}

ABARE-BRS, 2010. Environmentally Sustainable Diversion Limits in the Murraydarling Basin: Socioeconomic Analysis. Australian Bureau of Agricultural and Resource Economics, Canberra.

ABARE, 2007. Australian Commodities. Australian Bureau of Agricultural and Resource Economics, Canberra.

ABS, 2006. Value of Agricultural Commodities Produced. Australian Bureau of Statistics, Canberra.

ABS, 2011. Gross Value of Irrigated Agricultural Production, 2000-01 to 2009-10. Australian Bureau of Statistics, Canberra.

Adamson, D., Mallawaarachchi, T., Quiggin, J., 2009. Declining inflows and more frequent droughts in the Murray-Darling Basin: climate change, impacts and adaptation. Australian Journal of Agricultural and Resource Economics 53 (3), 345-366.

Allen, R.G., Pereira, L.S., Raes, D., Smith, M., 1998. Crop Evapotranspiration: Guidelines for Computing Crop Water Requirements. FAO Irrigation and Drainage Paper 56.

Beale, G.T.H., Beecham, R., Harris, K., O'Neill, D., Schroo, H., Tuteja, N.K., Williams, R.M., 2000. Salinity Predictions for NSW Rivers within the MurrayDarling Basin. Land and Water Conservation, NSW, Sydney.

Brooke, A., Kendrick, D., Meeraus, A., Raman, R., 2004. GAMS: a User's Guide. GAMS Development Corporation, Washington, DC.

BRS, 2004. Land Use mapping for the Murray-Darling Basin: 1993, 1996, 1998, 2000 maps. Bureau of Rural Sciences, Canberra.

Cai, X., 2008. Implementation of holistic water resources-economic optimization models for river basin management - reflective experiences. Environmental Modelling \& Software 23 (1), 2-18.

Chen, X.G., Onal, H., 2012. Modeling agricultural supply response using mathematical programming and crop mixes. American Journal of Agricultural Economics 94 (3), 674-686.

Chiew, F.H.S., Teng, J., Kirono, D., Frost, A.J., Bathols, J.M., Vaze, J., Viney, N.R., Young, W.J., Hennessy, K.J., Cai, W.J., 2008. Climate Data for Hydrologic Scenario Modelling across the Murray-Darling Basin. A report to the Australian Government from the CSIRO Murray-Darling Basin Sustainable Yields Project. CSIRO, Canberra, p. 35.

CSIRO, 2008. Water Availability in the Murray. A report to the Australian Government from the CSIRO Murray-Darling Basin Sustainable Yields Project. CSIRO, Canberra.

Doorenbos, J., Kassam, A.H., 1979. Yield Response to Water, FAO Irrigation and Drainage Paper: Rome.

Drake, B.G., Gonzalez-Meler, M.A., Long, S.P., 1997. More efficient plants: a consequence of rising atmospheric CO2? Annual Review of Plant Physiology and Plant Molecular Biology 48, 609-639.

Elmahdi, A., Connor, J., Doble, R., Stenson, M., Kirby, M., Walker, G., 2008. Forecasting Lower Murray River Salinity under Climatic Uncertainty and Reduced Dilution Flow. International Salinity Forum, Adelaide.

George, B., Malano, H., Davidson, B., Hellegers, P., Bharati, L., Massuel, S., 2011a. An integrated hydro-economic modelling framework to evaluate water allocation strategies I: model development. Agricultural Water Management 98 (5), 733-746.

George, B., Malano, H., Davidson, B., Hellegers, P., Bharati, L., Massuel, S., 2011b. An integrated hydro-economic modelling framework to evaluate water allocation strategies II: scenario assessment. Agricultural Water Management 98 (5), 747-758. 
Gomann, H., Kreins, P., Kunkel, R., Wendland, F., 2005. Model based impact analysis of policy options aiming at reducing diffuse pollution by agriculture - a case study for the river Ems and a sub-catchment of the Rhine. Environmental Modelling \& Software 20 (2), 261-271.

Grafton, R.Q., Jiang, Q., 2011. Economic effects of water recovery on irrigated agriculture in the Murray-Darling Basin. Australian Journal of Agricultural and Resource Economics 55 (4), 487-499.

Griffin, R.C., 2006. Water Resource Economics: The Analysis of Scarcity, Policies, and Projects. MIT Press, Cambridge, Mass.

Hafi, A., Thorpe, S., Foster, A., 2009. The impact of climate change on the irrigated agriculture industries in the Murray-Darling Basin, Australian Agricultural and Resource Economics Society Conference. ABARE Conference paper: Cairns.

Heckelei, T., Britz, W., 2005. Models based on positive mathematical programming: state of the art and further extensions. In: Arfini, F. (Ed.), Modelling Agricultura Policies: State of the Art and the New Challenges, Proceedings of the 89th European Seminar of the European Association of Agricultural Economists. Minte Universita, Parma Editore, pp. 48-73.

Heckelei, T., Wolff, H., 2003. Estimation of constrained optimisation models for agricultural supply analysis based on generalised maximum entropy. European Review of Agricultural Economics 30 (1), 27-50.

Howitt, R., MacEwan, D., Medellin-Azuara, J., Lund, J.R., 2010. Economic Modelling of Agriculture and Water in the California Using the Statewide Agricultural Production Model. A report for the California Department of Water Resources, CA Water Plan Update 2009. University of California, Davis.

Howitt, R.E., 1995. Positive mathematical-programming. American Journal of Agricultural Economics 77, 329-342.

Howitt, R.E., 2005. Agricultural and Environmental Policy Models: Calibration, Estimation and Optimization. University of California Davis, UC Davis.

Jakeman, A.J., Letcher, R.A., 2003. Integrated assessment and modelling: features, principles and examples for catchment management. Environmental Modelling \& Software 18 (6), 491-501.

Kaczan, D., Qureshi, M.E., Connor, J., 2011. Water Trade and Price Data for the Southern Murray Darling Basin. CSIRO, Adelaide. Canberra.

Kan, I., Schwabe, K.A., Knapp, K.C., 2002. Microeconomics of irrigation with saline water. Journal of Agricultural and Resource Economics 27, 16-39.

Kirby, M., Connor, J., Bark, R., Qureshi, M.E., Keyworth, S., 2012. The Economic Impact of Water Reductions during the Millennium Drought in the MurrayDarling Basin, AARES Conference: Perth.

Letey, J., Dinar, A., Knapp, K.C., 1985. Crop-water production function model for saline irrigation waters. Soil Science Society of America Journal 49, 1005-1009.

Mainuddin, M., Kirby, M., 2009. Spatial and temporal trends of water productivity in the lower Mekong River Basin. Agricultural Water Management 96 (11), 1567-1578.

Mallawaarachchi, T., Foster, A., 2009. Dealing with Irrigation Drought: the Role of Water Trading in Adapting to Water Shortages in 2007-08 in the Southern Murray-Darling Basin. Australian Bureau of Agricultural Economics Research Report 09(6). ABARE-BRS, Canberrra.
McCarl, B.A., 1982. Cropping activities in agricultural sector models: a methodological proposal. American Journal of Agricultural Economics 64 (4), 768-772.

MDBC, 2001. Integrated Catchment Management in the Murray-Darling Basin 2001-2010: Delivering a Sustainable Future (Canberra).

MDBC, 2002. Setting up of MSM-BIGMOD Modelling Suite for the River Murray System. Murray Darling Basin Commission, Canberra.

Merel, P., Bucaram, S., 2010. Exact calibration of programming models of agricultural supply against exogenous supply elasticities. European Review of Agricultural Economics 37 (3), 395-418.

NWC, 2007. Level 2 Baseline Assessment of Water Resources. National Water Commission, Canberra.

Oliver, M., Dyack, B., Ashton, D., 2009. Irrigation in the Murray-Darling Basin: Farms Trading Temporary Water in 2006-07. ABARE research report 09.8. ABARE-BRS, Canberra.

Paris, Q., Howitt, R.E., 1998. An analysis of ill-posed production problems using maximum entropy. American Journal of Agricultural Economics 80 (1), 124-138.

Quinn, N.W.T., Brekke, L. Miller, N.L., Heinzer, T. Hidalgo, H., Dracup, J.A., 2004. Model integration for assessing future hydroclimate impacts on water resources, agricultural production and environmental quality in the San Joaquin Basin, California. Environmental Modelling \& Software 19 (3), 305-316.

Qureshi, M.E., Connor, J., Kirby, M., Mainuddin, M., 2007. Economic assessment of acquiring water for environmental flows in the Murray Basin. Australian Journal of Agricultural and Resource Economics 51 (3), 283-303.

Qureshi, M.E., Schwabe, K., Connor, J., Kirby, M., 2010. Environmental water incentive policy and return flows. Water Resources Research 46. http:/ dx.doi.org/10.1029/2008wr007445.

Qureshi, M.E., Mainuddin, M., Marvanek, M., Elmahdi, A., Connor, J., Whitten, S. 2012. Irrigation Futures for the Murray Basin - Technical Documentation. CSIRO, Canberra, p. 33.

Qureshi, M.E., Proctor, W., Kirby, M., 2006. Economic Assessment of Water Trade Restrictions in the Murray Darling Basin, International Conference on Regional and Urban Modelling. Free University, Brussels.

Röhm, O., Dabbert, S., 2003. Integrating agri-environmental programs into regional production models: an extension of positive mathematical programming. American Journal of Agricultural Economics 85 (1), 254-265.

Schwabe, K.A., Kan, I., Knapp, K.C., 2006. Drainwater management for salinity mitigation in irrigated agriculture. American Journal of Agriculture Economics $88,135-149$.

\section{Further reading}

Kragt, M.E., Newham, L.T.H., Bennett, J., Jakeman, A.J., 2011. An integrated approach to linking economic valuation and catchment modelling. Environmental Modelling \& Software 26 (1), 92-102. 